\title{
Acute Renal Failure Secondary to Rhabdomyolysis as a Complication of Major Urological Surgery: The Experience of a High-Volume Urological Center
}

\author{
Armando E. De Gracia-Nieto ${ }^{a}$ Oriol Angerri ${ }^{a} \quad$ Jordi Bover $^{\mathrm{b}} \quad$ Daniel Salas $^{\mathrm{a}}$ \\ Juan Manuel Villamizar ${ }^{a}$ Humberto Villavicencio ${ }^{a}$ \\ Departments of a Urology and ${ }^{\mathrm{b}}$ Nephrology, Fundació Puigvert, Barcelona, Spain
}

\section{Key Words}

Acute renal failure $\cdot$ Rhabdomyolysis $\cdot$ Surgical

complication · Urology · Cystectomy · Urethroplasty

\begin{abstract}
Objective: The aim of this study was to determine the incidence of acute renal failure secondary to rhabdomyolysis (ARFSR) as a complication of major urological surgery (MUS), as well as to describe the clinical characteristics and identify possible risk and protective factors. Subjects and Methods: Cases of ARFSR due to MUS between January 1997 and August 2011 were identified using the institutional database. The incidence was estimated and the clinical characteristics were analyzed using simple scatterplot graphs to identify possible risk and protective factors. Results: In this period, 14,337 MUS procedures were performed, in which 4 cases suffered from ARFSR (the incidence rate was $0.03 \%$ ). The incidence rates after radical cystectomy and urethroplasty were $0.26 \%$ ( $3 / 1,175$ cases) and $0.15 \%$ ( $1 / 651$ cases), respectively. No case of rhabdomyolysis was reported among the patients who underwent other major surgical procedures. Two patients required dialysis, and all 4 patients recovered to their baseline renal function at an average of 11 days (7-
\end{abstract}

17) with the appropriate treatment. Male gender, younger age, lower ASA score, prolonged operative time, high body mass index, elevated preoperative serum creatinine and estimated blood loss were possible risk factors for developing ARFSR due to MUS. We found that a higher intraoperative administered volume was a possible protective factor. The operative position and type of surgery seemed to play minor roles. Early diagnosis and treatment possibly leads to an improved outcome. Conclusion: In our study, ARFSR due to MUS was a rare entity and had a good prognosis. It was more frequent as a complication of radical cystectomy. Further studies are required to confirm our findings.

(c) 2016 S. Karger AG, Basel

\section{Introduction}

Rhabdomyolysis is a syndrome that involves skeletal muscle necrosis and lysis followed by the release of intracellular content to peripheral blood, which may cause electrolyte imbalance, cardiac arrhythmias and multifactorial acute renal failure (ARF) [1]. As a surgical complication it is rare, but it can become life threatening [2]. Previous studies have reported isolated cases of ARF sec-

\begin{tabular}{ll}
\hline KARGER & $\begin{array}{l}\text { ○ 2016 S. Karger AG, Basel } \\
1011-7571 / 16 / 0254-0329 \$ 39.50 / 0 \quad \text { Karger }\end{array}$ \\
E-Mail karger@karger.com & $\begin{array}{l}\text { Thisis an Open Access article licensed under the terms of the } \\
\text { Creative Commons Attribution-NonCommercial 3.0 Un- } \\
\text { ported license (CC BY-NC) (www.karger.com/OA-license), } \\
\text { applicable to the online version of the article only. Distribu- } \\
\text { tion permitted for non-commercial purposes only. }\end{array}$
\end{tabular}

Armando E. De Gracia Nieto

Fundació Puigvert

c/Cartagena 340-350

ES-08025 Barcelona (Spain)

E-Mail armandodg@ hotmail.com 
ondary to rhabdomyolysis (ARFSR) as a complication of a urological intervention [2-10], as well as a few series of ARFSR for specific urological surgical interventions or positions [11-14]. We evaluated the incidence, clinical features, possible risk and protective factors, and progress of patients affected with ARFSR as a complication of major urological surgery (MUS) in a high-volume monographic urological center.

\section{Materials and Methods}

Using our hospital database, a retrospective review was carried out to identify patients in whom MUS had been performed in order to determine the cases of rhabdomyolysis diagnosed at our institution between January 1997 and August 2011. Among these cases, those in which ARFSR occurred as a complication of MUS were determined. Inclusion criteria for MUS were any urological intervention with an expected surgical time of greater than $1 \mathrm{~h}$ and an expected hospital stay of 2 or more days. We also estimated the incidence of ARFSR secondary to MUS in general and per procedure, and investigated the clinical characteristics of these patients, identifying potential risk factors and their development. The data collected included age, sex, body mass index (BMI), comorbidities, medical history, regular medication, American Society of Anesthesiologists (ASA) physical status classification system score, type of urological intervention, operative position, operative time, intraoperative estimated blood loss (IOBL), preoperative serum creatinine $(\mathrm{Cr})$, potassium $\left(\mathrm{K}^{+}\right)$and estimated glomerular filtration rate (eGFR), intraoperatively administered volume (IOAV), postoperative symptoms and complications, and time from surgery to the diagnosis of ARFSR due to MUS. The outcome variables were postoperative serum $\mathrm{Cr}$ kinase $(\mathrm{CK})$ at diagnosis, postoperative peak $\mathrm{CK}$, peak $\mathrm{K}^{+}$, peak $\mathrm{Cr}$ and the lowest postoperative eGFR, number of dialyses needed, $\mathrm{Cr}$ at discharge and time to recover renal function. A simple scatterplot graph analysis was carried out between continuous variables in order to identify any relevant correlations between them.

\section{Results}

Between January 1997 and August 2011, we performed 14,337 MUS procedures at our center. In this period, 40 cases of ARFSR were diagnosed for various medical or surgical conditions. Of these cases, 5 were postsurgical, of which 4 occurred as a complication of MUS and 1 as a complication of a vascular surgery (aortic aneurysm). Of the 4 cases following MUS, 3 were due to radical cystectomy (robot-assisted in 1 patient and open surgery in 2 patients) and 1 due to urethroplasty. No case was reported following other major interventions, including radical prostatectomies, nephrectomies and endourological procedures. No case was reported in a lateral position. The incidence rate of ARFSR as a complication of MUS was 3 cases per 10,000. During this period, 1,175 radical cystectomies and 651 urethroplasties were performed, so the incidence for these two procedures was 0.26 and $0.15 \%$, respectively.

The mean age of the 4 patients with ARFSR as a complication of MUS was $56 \pm 12.2$ years (range 38-65, median 60), all were male, the mean BMI was $27.7 \pm 4.6$ (range 24.1-33.3) and the mean preoperative $\mathrm{Cr}$ was $103.8 \pm 34.7 \mu \mathrm{mol} / \mathrm{l}$ (range $76-154$ ). The preoperative patient characteristics are summarized in table 1 . Two of our 4 cases were treated with statins, and 1 of these 2 with atorvastatin and fibrates (gemfibrozil) together. Three of our 4 patients were asthmatic. The mean operating time was $368 \pm 52 \mathrm{~min}$ (range 330-445), the IOBL ranged from 100 to $4,000 \mathrm{ml}$ (mean of $900 \mathrm{ml}$ ) and the mean IOAV was $4,075 \pm 1,090 \mathrm{ml}$ (range 2,500-5,000). The characteristics of the performed surgeries are summarized in table 2 .

The average time between surgery and diagnosis of ARFSR was 6 days (range 1-14). The treatment was based on hydration and/or intravenous alkalization. Two patients required hemodialysis (three and seven sessions, respectively). All 4 patients recovered their baseline renal function after an average of 11 days (range 7-17) from the diagnosis of ARFSR. The evolution of these cases is summarized in table 3 .

A simple scatterplot graph analysis was performed (fig. 1), which showed a positive correlation between BMI and peak $\mathrm{K}^{+}$and with $\mathrm{Cr}$ at discharge, and a negative correlation between BMI and postoperative eGFR. Also, a positive association between preoperative $\mathrm{Cr}$ and peak $\mathrm{CK}$ and a negative association with postoperative eGFR was noted. In addition, we found a positive association between IOBL and CK at diagnosis and a negative association with preoperative eGFR. Moreover, a positive association between ASA score and IOAV and with the lowest eGFR, and a negative association between ASA score and peak $\mathrm{Cr}$ and with time to basal $\mathrm{Cr}$ was detected. $\mathrm{We}$ also noted a negative association between IOAV and peak Cr. Finally, a positive graphical correlation was seen between age and postoperative eGFR. However, confirmational statistical tests were not performed due to the small sample size $(\mathrm{n}=4)$.

\section{Discussion}

In this study ARFSR due to MUS affected only 4 cases out of 14,337 procedures performed during the 15-year period, thereby indicating either the rarity of this entity or its underdiagnosis. In our study, $100 \%$ of the cases of 
Table 1. Clinical characteristics of the 4 patients with ARFSR as a complication of MUS

\begin{tabular}{|c|c|c|c|c|c|c|c|c|}
\hline $\begin{array}{l}\text { Patient } \\
\text { No. }\end{array}$ & $\begin{array}{l}\text { Age, } \\
\text { years }\end{array}$ & BMI & Comorbidities and medical history & Regular medication & ASA & $\begin{array}{l}\text { Cr preQx, } \\
\mu \mathrm{mol} / \mathrm{l}\end{array}$ & $\begin{array}{l}\mathrm{K}^{+} \\
\text {preQx, } \\
\mathrm{mmol} / \mathrm{l}\end{array}$ & $\begin{array}{l}\text { eGFR } \\
\mathrm{preQx}, \mathrm{ml} / \\
\mathrm{min} / 1.73 \mathrm{~m}^{2}\end{array}$ \\
\hline 2 & 65 & 23.7 & $\begin{array}{l}\text { Diabetes mellitus type I; cancer of the glans } \\
\text { penis, pT3N0M0, treated with glansectomy plus } \\
\text { bilateral inguinal lymphadenectomy; smoking } \\
30 \text { cigarettes/day }\end{array}$ & $\begin{array}{l}\text { Aspirin, atorvastatin, bisoprolol, } \\
\text { omeprazole, insulin, diazepam }\end{array}$ & 3 & 76 & 4.8 & 89 \\
\hline 3 & 38 & 29.8 & Asthmatic bronchitis & None & 1 & 87 & 4.2 & $>90$ \\
\hline 4 & 60 & 33.3 & $\begin{array}{l}\text { Former smoker for } 6 \text { months having previously } \\
\text { smoked } 30 \text { - } 40 \text { cigarettes/day, hypertension, } \\
\text { asthmatic bronchitis, chronic obstructive } \\
\text { pulmonary disease, type } 2 \text { diabetes mellitus, } \\
\text { ischemic heart disease }\end{array}$ & $\begin{array}{l}\text { Metformin, torasemide, } \\
\text { tiotropium, gemfibrozil, losartan, } \\
\text { allopurinol, atorvastatin, aspirin, } \\
\text { fluticasone/salmeterol inhaler, } \\
\text { fosinopril }\end{array}$ & 3 & 154 & 4.2 & 45 \\
\hline
\end{tabular}

Cr preQx = Preoperative $\mathrm{Cr}$; $\mathrm{K}^{+}$preQx = serum $\mathrm{K}^{+}$prior to surgery; eGFR preQx = eGFR estimated by the MDRD equation prior to surgery.

Table 2. Characteristics of the surgical procedures performed on the 4 patients with ARFSR following MUS

\begin{tabular}{|c|c|c|c|c|c|c|c|}
\hline $\begin{array}{l}\text { Patient } \\
\text { No. }\end{array}$ & Surgery & $\begin{array}{l}\mathrm{ST} \\
\mathrm{min}\end{array}$ & Position & $\begin{array}{l}\text { IOBL, } \\
\mathrm{ml}\end{array}$ & $\begin{array}{l}\text { IOAV, } \\
\mathrm{ml}\end{array}$ & $\begin{array}{l}\text { eGFR, } \\
\mathrm{ml} / \mathrm{min} / 1.73 \mathrm{~m}^{2} \\
\text { postQx }\end{array}$ & Postoperative symptoms \\
\hline 2 & $\mathrm{RC}+\mathrm{IC}+\mathrm{BL}$ & 345 & $S+F$ & 800 & 5,000 & 86 & Pain in the right lower limb \\
\hline 3 & Complex urethroplasty & 352 & FL & 100 & 2,500 & $\mathrm{~N} / \mathrm{A}$ & $\begin{array}{l}\text { Pain and edema of both lower extremities in } \\
\text { the medial proximal third }\end{array}$ \\
\hline
\end{tabular}

Table 3. Characteristics of the postsurgical outcome in the 4 patients with ARFSR following MUS

\begin{tabular}{|c|c|c|c|c|c|c|c|c|c|}
\hline $\begin{array}{l}\text { Patient } \\
\text { No. }\end{array}$ & $\begin{array}{l}\text { Qx-Dx t, } \\
\text { days }\end{array}$ & $\begin{array}{l}\text { CK-Dx, } \\
\text { IU/dl }\end{array}$ & $\begin{array}{l}\text { Lowest } \\
\text { eGFR, } \mathrm{ml} / \\
\mathrm{min} / 1.73 \mathrm{~m}^{2}\end{array}$ & $\begin{array}{l}\text { Peak Cr, } \\
\mu \mathrm{mol} / \mathrm{l}\end{array}$ & $\begin{array}{l}\text { Peak K+, } \\
\mathrm{mmol} / \mathrm{l}\end{array}$ & $\begin{array}{l}\text { Peak CK, } \\
\text { IU/dl }\end{array}$ & HD & $\begin{array}{l}\mathrm{Cr} \\
\text { discharge, } \\
\mu \mathrm{mol} / \mathrm{l}\end{array}$ & $\begin{array}{l}\mathrm{t} \text { basal } \mathrm{Cr} \text {, } \\
\text { days }\end{array}$ \\
\hline 2 & 14 & 797 & 15 & 353 & 4.3 & 797 & 3 & 89 & 9 \\
\hline 3 & 8 & 425 & 4 & 1,196 & 6.8 & 1,367 & 7 & 108 & 17 \\
\hline 4 & 2 & 5,540 & 17 & 380 & 6.86 & 11,239 & No & 120 & 7 \\
\hline
\end{tabular}

Qx-Dx $\mathrm{t}=$ Elapsed time between surgery and diagnosis; CK-Dx = serum CK level at the time of diagnosis; lowest eGFR = lowest eGFR estimated by the MDRD equation after surgery; peak $\mathrm{Cr}=$ highest serum $\mathrm{Cr}$ level after diagnosis; peak $\mathrm{K}^{+}=$highest serum $\mathrm{K}^{+}$level after diagnosis; peak $\mathrm{CK}=$ highest serum $\mathrm{CK}$ level after diagnosis; $\mathrm{HD}=$ number of hemodialysis sessions; $\mathrm{No}=$ not required; $\mathrm{Cr}$ discharge $=$ value of serum $\mathrm{Cr}$ at discharge; $\mathrm{t}$ basal $\mathrm{Cr}=\mathrm{time}$ from diagnosis to recovery of baseline serum $\mathrm{Cr}$. 
Fig. 1. Simple scatterplot graph analysis. Some associations were found between the variables.

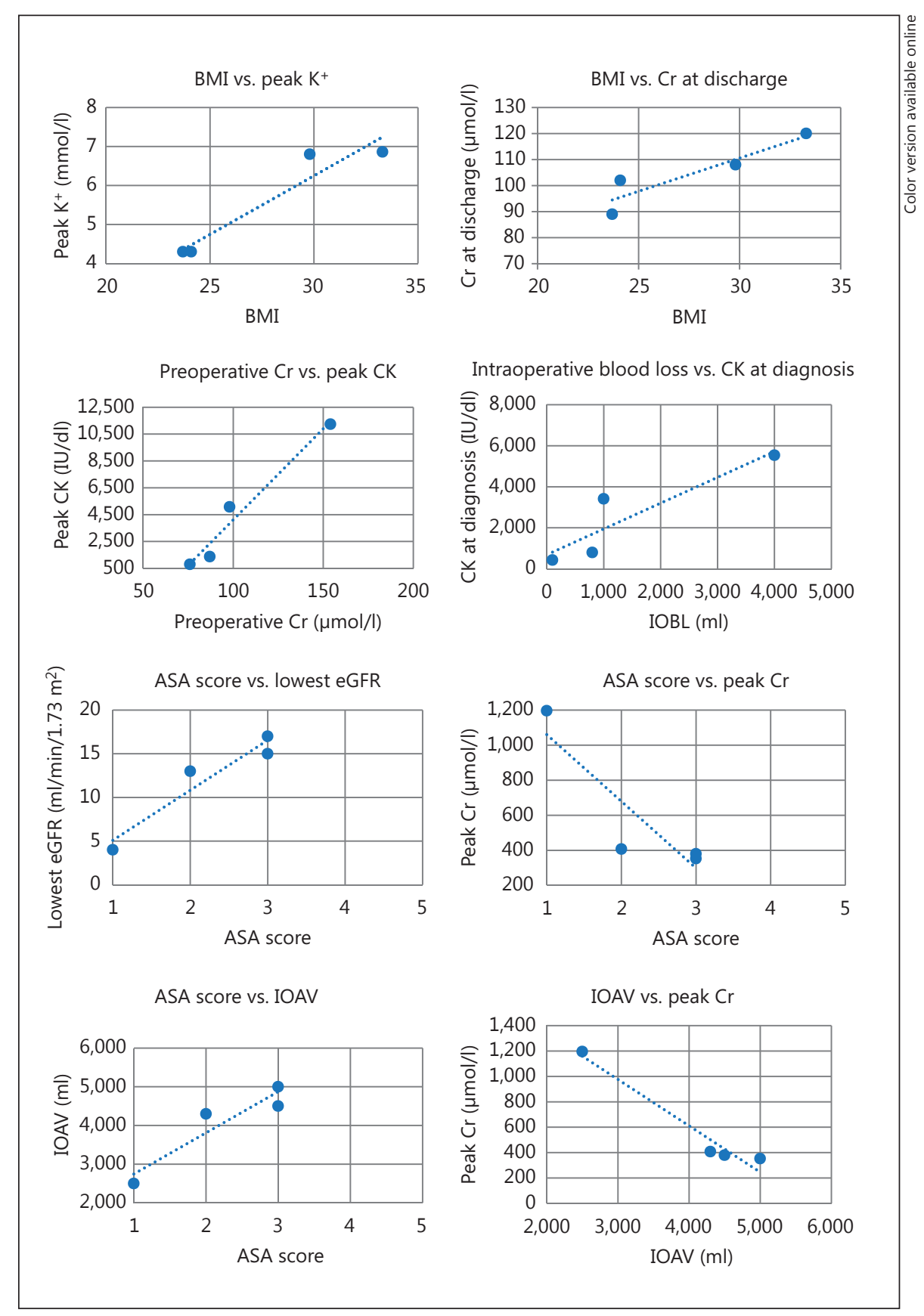

ARFSR had an operative time of $>5 \mathrm{~h}$. Also, $100 \%$ of the cases occurred in male patients. Our simple scatterplot analysis showed that younger age, lower ASA score, elevated BMI, higher preoperative Cr and high IOBL may be possible risk factors, whilst a higher IOAV may be a protective factor. Older age as a protective factor could be explained by the reduced muscular mass characteristic of the elderly. A low ASA score as a risk factor might be jus- tified by the awareness and high suspicious index of the sanitary personnel when patients have a higher ASA score. This is supported by the finding that a higher ASA score was also related to a higher IOAV, which also seems to be a protective factor.

Suggested risk factors for postsurgical rhabdomyolysis in the published literature include: male gender (greater muscle mass), particular surgical positions (forced lithot- 
Table 4. Causes of rhabdomyolysis

Traumas and accidents

Use of illicit drugs (heroin, cocaine, amphetamines, barbiturates)

Abuse of legal drugs (alcohol, caffeine)

Toxins (ethylene glycol, methanol)

Medications (statins, salicylates, fibrates, benzodiazepines, corticosteroids, theophylline, tricyclic antidepressants, selective inhibitors of serotonin reuptake, methadone)

Muscle diseases (muscular dystrophy, myositis)

Neuroleptic malignant syndrome (associated with the consumption of neuroleptics)

Malignant hyperthermia syndrome (associated with the use of neuromuscular blocking)

Seizures

Prolonged immobilization (e.g. unconsciousness, surgeries)

Infections

Strenuous exercises

Exposure to extreme temperatures

Sickle cell disease

Idiopathy omy, lateral flexed decubitus), prolonged operative time ( $>5$ h), BMI $>28$ (obesity, well-developed muscles), hypovolemia, diabetes mellitus, previous renal disease, hypertension and certain medications $[1,9,12,15-19]$. The condition has most frequently been described after urological procedures in which the forced lithotomy position was used $[2,5,6,8,12,13,20]$.

In our study, this position was present in just 1 out of the 4 cases of ARFSR due to MUS with an incidence in urethroplasties of $0.15 \%$. Also, there were no cases of ARFSR after laparoscopic nephrectomies (LN) or prostatectomies. In our study, the supine position with flexion was used in the other 3 cases (cystectomies). According to Anema et al. [15] the incidence of rhabdomyolysis following surgery using the lithotomy position is $1 \%$. The incidence of ARFSR after an LN has been described to be between 0 and $4.9 \%[11,12,21]$. Lately it has been reported that up to $33 \%$ of cases occurring after an LN correspond to living donors (younger patients with a greater muscle mass) [11]. In the literature, we found no series of ARFSR after cystectomies. Although the published data suggest that the operative position and type of surgery may be possible risk factors, we suggest that they play a minor role in the development of ARFSR.

Two of our 4 cases were treated with statins, and 1 of these 2 with atorvastatin and fibrates (gemfibrozil) together. Both of these patients were diabetic. It is known that certain drugs can cause rhabdomyolysis (table 4) [1].
Statin therapy is associated with rhabdomyolysis and the risk increases when statins are administered in conjunction with fibrates, especially gemfibrozil. The relative risk associated with this medication is higher in elderly patients and those with diabetes mellitus [18, 19,22, 23]. Cases of ARFSR have been described after asthma attacks [24]. Three of our patients were asthmatic ( $3 / 4$ cases), but none had a crisis reported during the postoperative period.

Interestingly, the patient in our series (No. 4; table 1) in whom ARFSR as a complication of MUS was associated with the greatest muscle damage (higher peak of serum CK) also had the highest number of risk factors for ARFSR and the highest surgical risk (ASA 3). This patient (aged 60 years) had the highest BMI (33.3), the highest IOBL $(4,000 \mathrm{ml})$, diabetes mellitus and hypertension, and was also treated with gemfibrozil and atorvastatin. However, the diagnosis was made on the first postoperative day, so early treatment was started and dialysis was not needed despite preexisting elevated serum $\mathrm{Cr}$, which we identified as a possible risk factor (table 3 ). This patient required lower limb physiotherapy during the postoperative period (Clavien-Dindo grade I). In contrast, the youngest patient in our series (No. 3, aged 38 years), who had well-developed musculature and the lowest surgical risk and did not take regular medication, underwent a complex urethroplasty using the forced lithotomy position with a low IOBL (100 ml). He developed postoperative pain and edema of both lower limbs, which was initially suspected to be due to a deep vein thrombosis, delaying the diagnosis. This patient was one of the 2 patients with the latest diagnosis (8 days postsurgery), and seven dialysis sessions were required (Clavien-Dindo grade IVa). These data suggest the importance of early diagnosis and treatment in the evolution of this syndrome.

The limitations of our work include this being a retrospective, nonrandomized, noncontrolled study of a rare and multifactorial surgical complication in which no statistical analysis was performed to confirm the findings between associations due to the small sample size ( $\mathrm{n}=$ $4 / 14,337)$. There are several papers published about the subject, but to our knowledge, because of the data provided, this is the first study of its kind.

The most frequent causes of rhabdomyolysis are summarized in table $4[1,25]$. It is important to identify the risk factors and to try to correct them when considered appropriate. In the forced lithotomy position, when more than $5 \mathrm{~h}$ of surgery is expected, it is recommended to include a pause to lower the legs [15]. Regarding the lateral decubitus position with flexion or the flexed supine position, one should try to flex as little as possible 
$[11,16]$. Although in empirical practice it is recommended that pads should be placed between the patient and the high-pressure contact surfaces with the table, no benefit to their use has been demonstrated [17]. In fact, in a study in which patients in the lateral decubitus position with flexion were assessed with and without the use of gel pads, the pads were found to increase the interface pressures between the skin and the contact surfaces of the operating room tables [16]. Perioperatively, adequate hydration must be maintained and hypotension avoided [17].

Despite very little scientific evidence, progress has been made in the prevention and treatment of rhabdomyolysis due to trauma in major disasters [26]. Hydration with saline is the mainstay of treatment $[1,12]$. Diuresis should be maintained at between 200 and $300 \mathrm{ml} / \mathrm{h}$. It has been shown in animal models that the replacement fluids, urinary alkalization and increased diuresis offer protection against ARF [12]. Fluids containing $\mathrm{K}^{+}$should be avoided [1]. Intravenous hydration is recommended at above 6 liters/day in patients with severe rhabdomyolysis $(\mathrm{CK} \geq 15,000 \mathrm{IU} / \mathrm{l})$ and at 3-6 liters/day in less severe cases, with close monitoring of diuresis and the weight of the patient if possible, in order to avoid overhydration in oligoanuric patients [26].

Treatment with mannitol and loop diuretics is controversial but intravenous sodium bicarbonate (to maintain urine $\mathrm{pH}>6.5$ ) decreases the precipitation of myoglobin and uric acid. Sodium bicarbonate should be avoided in patients with hypercalcemia or hyperphosphatemia to avoid the possible precipitation of calcium and phosphorus. In patients with a good response to saline, mannitol administration or diuretics should be avoided. Electrolyte imbalances should be corrected and drugs that might favor rhabdomyolysis should be suspended (table 4). If there is continuous muscular damage or compartment syndrome, fasciotomy should be performed. As many sessions of dialysis should be performed as are needed [1]. Some patients may later need prolonged physical therapy and pain management [11].

\section{Conclusions}

In the present study, ARFSR due to MUS was a rare entity and had a good prognosis. Male gender, younger age, lower ASA score, prolonged operative time, high $\mathrm{BMI}$, elevated preoperative serum $\mathrm{Cr}$ and high IOBL may be possible risk factors for developing ARFSR due to MUS; a higher IOAV may be a protective factor, and it was more frequent as a complication of radical cystectomy. It appeared that the operative position and type of surgery might play a minor role in the development of ARFSR. Three out of 4 patients had a medical record of asthmatic bronchitis. Also, early diagnosis and treatment may improve the outcome. We recommend the identification of risk factors and early diagnosis and treatment, which may improve the outcome of these patients. The small sample size was a limitation of our study and further studies are required to confirm our findings.

\section{References}

1 Khan FY: Rhabdomyolysis: a review of the literature. Neth J Med 2009;67:272-283.

2 Bruce RG, Kim FH, McRoberts W: Rhabdomyolysis and acute renal failure following radical perineal prostatectomy. Urology 1996; 47:427-430.

- 3 Alterman I, Sidi A, Azamfirei L, et al: Rhabdomyolysis: another complication after prolonged surgery. J Clin Anesth 2007;19:6466.

4 Brown JA: Lateral gluteal myonecrosis in a patient undergoing partial nephrectomy in the modified flank position. Urology 2003;61: 462.

5 Iser IC, Senkul T, Reddy PK: Major urologic surgery and rhabdomyolysis in two obese patients. Int J Urol 2003;10:558-560.
6 Kikuno N, Urakami S, Shigeno K, et al: Traumatic rhabdomyolysis resulting from continuous compression in the exaggerated lithotomy position for radical perineal prostatectomy. Int J Urol 2002;9:521-524.

7 Kuang W, Ng CS, Matin S, et al: Rhabdomyolysis after laparoscopic donor nephrectomy. Urology 2002;60:911.

8 Orihuela E, Nazemi T, Shu T: Acute renal failure due to rhabdomyolysis associated with radical perineal prostatectomy. Eur Urol 2001;39:606-609.

9 Rehman J, Boglia J, Chughtai B, et al: High body mass index in muscular patients and flank position are risk factors for rhabdomyolysis: case report after laparoscopic live-donor nephrectomy. J Endourol 2006;20:646-650.
10 Weber B, Todd G, Moore RB: Rhabdomyolysis following renal autotransplantation. Can Urol Assoc J 2008;2:57-60.

-11 Glassman DT, Merriam WG, Trabulsi EJ, et al: Rhabdomyolysis after laparoscopic nephrectomy. JSLS 2007;11:432-437.

12 Reisiger KE, Landman J, Kibel A, et al: Laparoscopic renal surgery and the risk of rhabdomyolysis: diagnosis and treatment. Urology 2005;66:29-35.

13 Vijay MK, Vijay P, Kundu AK: Rhabdomyolysis and myogloginuric acute renal failure in the lithotomy/exaggerated lithotomy position of urogenital surgeries. Urol Ann 2011;3: 147-150.

14 Nimmo GR, Stewart SM, English PJ: Myoglobinuric acute renal failure associated with major urological surgery - an avoidable problem? Intensive Care Med 1988;14:244-245. 
15 Anema JG, Morey AF, McAninch JW, et al: Complications related to the high lithotomy position during urethral reconstruction. J Urol 2000;164:360-363.

16 Deane LA, Lee HJ, Box GN, et al: Third prize: flank position is associated with higher skinto-surface interface pressures in men versus women: implications for laparoscopic renal surgery and the risk of rhabdomyolysis. J Endourol 2008;22:1147-1151.

17 Shaikh S, Nabi G, McClinton S: Risk factors and prevention of rhabdomyolysis after laparoscopic nephrectomy. BJU Int 2006;98:960962.

18 Duell PB, Connor WE, Illingworth DR: Rhabdomyolysis after taking atorvastatin with gemfibrozil. Am J Cardiol 1998;81:368-369.
19 Layne RD, Sehbai AS, Stark LJ: Rhabdomyolysis and renal failure associated with gemfibrozil monotherapy. Ann Pharmacother 2004;38:232-234.

20 Bildsten SA, Dmochowski RR, Spindel MR, et al: The risk of rhabdomyolysis and acute renal failure with the patient in the exaggerated lithotomy position. J Urol 1994;152:19701972.

21 Breda A, Veale J, Liao J, et al: Complications of laparoscopic living donor nephrectomy and their management: the UCLA experience. Urology 2007;69:49-52.

22 Amend KL, Landon J, Thyagarajan V, et al: Incidence of hospitalized rhabdomyolysis with statin and fibrate use in an insured us population. Ann Pharmacother 2011;45: $1230-1239$.
23 Graham DJ, Staffa JA, Shatin D, et al: Incidence of hospitalized rhabdomyolysis in patients treated with lipid-lowering drugs. JAMA 2004;292:2585-2590.

24 Mehta R, Fisher LE Jr, Segeleon JE, et al: Acute rhabdomyolysis complicating status asthmaticus in children: case series and review. Pediatr Emerg Care 2006;22:587-591.

25 Giannoglou GD, Chatzizisis YS, Misirli G: The syndrome of rhabdomyolysis: pathophysiology and diagnosis. Eur J Intern Med 2007;18:90-100

26 Iraj N, Saeed S, Mostafa H, et al: Prophylactic fluid therapy in crushed victims of Bam earthquake. Am J Emerg Med 2011;29:738-742. 